\title{
Narratives of Puerperal Women about Pregnancy and Risk Prenatal Care
}

Nayara Sousa de Mesquita1, Patrícia Moreira Collares', Bruna Karen Cavalcante Fernandes ${ }^{1}$, Natana Abreu de Moura1, Antonia Regynara Moreira Rodrigues ${ }^{1}$, Pamela Nery do Lago ${ }^{1}$, Hilana Dayana Dodou1, Dafne Paiva Rodrigues ${ }^{1}$

\section{Abstract}

Introduction: Pregnancy is a physiological phenomenon and therefore its evolution usually occurs uneventfully. However, it can pose risks for both the mother and the fetus and there are a number of women who, due to particular characteristics, are more likely to unfavorable evolution, which are called high-risk pregnancies. Therefore, this study aimed to know, from the narratives of mothers discharged from the Intensive Care Unit, the main doubts and complaints about pregnancy and risk prenatal care and describe the therapeutic itinerary throughout pregnancy.

Method: Descriptive, qualitative study conducted in the homes of mothers enrolled in basic health services of the $4^{\text {th }}$ Regional Unit in Fortaleza, Ceará, Brazil, from January to February 2015. A total of 10 mothers participated through narrative interview technique. For data analysis, authors adopted the proposal by Gomes and Mendonça and Gomes.

Results and Discussion: Questions were directed to the pathology. The difficulties in the consultation were inadequate communication, focus on disease, difficulty in following guidelines and lack of explanations aimed at childbirth, nutrition, breastfeeding, later childcare and insufficient emphasis on emotional aspects. In addition, there were difficulties along the therapeutic path.

Conclusion: It was noted the importance of carrying out actions/ strategies that enable the realization of a resolute care.
1 State University of Ceará, Fortaleza, Ceará, Brazil.

Contact information:

Nayara Sousa de Mesquita.

Address: Naturalista Feijó, 1010, Monte Castelo. State University of Ceará, Fortaleza, Ceará, Brazil.

”nayara_sousadm@hotmail.com

Keywords

Prenatal Care; Pregnancy Complications; Clinical Procedures. 


\section{Introduction}

Pregnancy is an important moment in a woman's life, marked by adaptations in every way, physical and emotional, existential and sexual, and, thus, a period in which women need guidance and care specific to meet their needs.

It is important to consider that in pregnancy, even with the important anatomic, endocrine, immunological and hemodynamic changes that occur in this period, it is maintained a dynamic equilibrium by compensatory mechanisms still little known. The boundary between normality and pathology is fine and its imbalance is a risk of maternal-fetal morbidity and mortality [1].

In this context, some factors may be present and may become potential risk of complications to the health of mothers and children. Some of the elements that constitute as risks may be present even before the occurrence of pregnancy, such as age, structural abnormalities in the reproductive organs; insecure marital status; family conflicts; low education level; dependence on licit or illicit drugs; and exposure to occupational hazards Other risk factors, however, may arise during pregnancy: hypertension; heart disease; gestational diabetes; premature birth, among others [2].

In Brazil, maternal death is still considered a public health problem. In the year 2007, there were 1,370 new cases of maternal deaths from direct obstetric causes, resulting from maternal risk factors and pregnancy complications [3]. Despite the numerous programs and actions to promote women's health that have been developed over many decades in Brazil, the reduced risks of pregnancy with consequent improvement in maternal health indicators is still below what was agreed, which was reducing by $75 \%$ maternal and neonatal mortality rates by 2015 [4].

In this scenario, it is noticeable the importance of adequate prenatal care, as maternal morbidity and mortality rates during pregnancy and childbirth are still high. In Brazil, despite all the advances in obstetric care, maternal and perinatal morbidity and mortality remains high, incompatible with the current level of economic and social development of the country [2]. Within this context, an important indicator of maternal morbidity is the need for patient transfer in the puerperal-pregnancy cycle to the Intensive Care Unit (ICU).

Given these considerations and believing in the influence of the quality of prenatal care to minimize the appearance of complications and the need to transfer to the ICU, the following question was delimited: what are the main doubts and health complaints in relation to pregnancy and prenatal care and what is the therapeutic journey of mothers discharged from ICU due to high-risk pregnancy?

The study is relevant because it is believed that knowledge of questions and complaints of these mothers discharged from ICU regarding pregnancy and therapeutic journey can contribute to the adoption of better behavior by health professionals. Additionally, it may promote the construction of a health support prenatal technology in order to cooperate and assist in the work of health professionals.

When there is a high-risk pregnancy, it will sometimes incur in need of more complex and sophisticated technology procedures, requiring assistance in a care level capable of solving front the presented difficulty. Knowing the therapeutic journey of these women in high-risk pregnancy condition is valuable in view of reducing the complications that occur during pregnancy. The therapeutic journey of this audience is understood here as the trajectory experienced by pregnant women during their prenatal care [5].

In this perspective, the study aimed to know, from the narratives of mothers discharged from ICU, the main questions and complaints about pregnancy and risk prenatal care and to describe the therapeutic journey throughout pregnancy. 


\section{Method}

This is a descriptive study with qualitative approach, carried out in the homes of mothers discharged from ICU and registered in basic health services, located in the $4^{\text {th }}$ Regional Unit in Fortaleza, Ceará. The population and study sample was composed of these mothers, who were tracked by the author of the research from childcare monitoring and with the contribution of the unit's community health workers.

The inclusion criteria were: mothers with a history of high-risk pregnancy, discharged from ICU, registered in the basic service of the $4^{\text {th }}$ Regional Unit, who have made at least one prenatal consultation in the Family Health Strategy; and exclusion criteria were: mothers with physical or mental restrictions that prevented the understanding of the study, identified through simple questions about space and time. After the application of the criteria and considering the theoretical saturation [6], the sample consisted of 10 mothers.

Data was collected between January and February 2015 by using the narrative interview technique. The Narrative Interview was guided by an individual interview script, consisting of the main question "What were your doubts and health complaints in relation to pregnancy and how they were approached by health professionals during the prenatal care?"; and the examining question: "Report your therapeutic journey sequentially and chronologically, regarding the health services you resorted throughout pregnancy". Furthermore, the sociodemographic and obstetric profile of participants was raised. Interviews were recorded with permission of the participants, identified by the letter "E" followed by the Arabic number corresponding to the order in which they were held.

The analysis method favored the interpretation of meanings and is based on the following steps: 1) understanding the context of representations of respondents with exhaustive reading of the material; 2) focus on structural aspects of the narrative;
3) finally, an interpretive synthesis was drawn up, in which the lines related with the socio-historical context, from the discussion of thematic axis, with reference to the theoretical and conceptual frameworks identified in the statements of the respondents [7-8].

The study was approved by the Research Ethics Committee of the University of Fortaleza, under opinion number 189251/2012 and the ethical and respected the legal principles involving human research recommended by Resolution No. 466/12 of the National Health Council [9]. All participants were informed about the study objectives and consented to participate by signing the Informed Consent Form (ICF). For those mothers under the age of 18, the ICF was signed by their legal guardians and the puerperal woman signed the Informed Consent Term (ICT).

\section{Results and Discussions}

\section{Profile of Study Participants}

The women were characterized as young, aged between 15 and 32 years old and average of 24.7 years old, with three teenagers between 15 and 18 years of age. Of the total of respondents, seven women were married and the other three were single. All women in the study were from Fortaleza. According to the self-declared color, seven considered themselves nonwhite (five black and two brown) and three classified themselves as white.

About education, only two women had completed high school, two had higher education and three of them were still in elementary school. The others mentioned dropping out from school, characterizing the sample as low education. It was also found that three of them did not perform paid work, but performed functions in the home. The other seven women performed paid functions, namely: teacher, maid, seamstress and dishwasher. 
Regarding family income, there was the following distribution: three mothers had an income below the minimum wage; five had income corresponding to a minimum wage; two had an income of two minimum wages. It is noteworthy that both low education and low income are considered risk factors for pregnancy complications [2].

Another important point is that the majority of respondents are married, a favorable factor, since many studies suggest that the partner may be a source of support. Marriage brings greater stability in marital relations, which can facilitate the sharing of responsibilities and difficulties experienced in everyday life [10].

With regard to clinical and obstetrical conditions, the sample was composed of six multipara and four primipara women. All women had cesarean delivery, justified by the high-risk pregnancy condition. It is noteworthy that the indiscriminate use of cesarean section has become an important public health problem because it can lead to increased cost and mortality to both the mother and the child [11] and in many risk pregnancies the normal delivery can be considered the most appropriate, however, professionals must pay attention to the pregnant woman's condition.

All participants underwent prenatal care initially in basic health care, but mentioned the need to have their prenatal accompanied at the secondary level institutions, because they have complications. When the pregnant woman is referred to a specialist service in high-risk prenatal care it is important that she is oriented not lose the link to the primary care. Thus, this team should monitor the evolution of pregnancy and treatments administered to the pregnant women through counterreference and active search of pregnant women in their territory of operation, carried out through home visits [5].

Regarding the diagnosis of illness presented during pregnancy, eight women were diagnosed with mild preeclampsia, one with gestational diabe- tes and hypertension and one had infection with Human Immunodeficiency Virus-HIV. All illnesses occurring during pregnancy should be treated appropriately, and it is noteworthy that in the global public health scenario hypertension in pregnancy deserves special attention. Currently, it is the third cause of maternal mortality in the world and the first in Brazil [12].

In addition, all participants reported that pregnancy had great interference in their lives. This was revealed when they were asked about which grade they would give, from 0 to 10 , for the degree of influence that pregnancy had on their lives, and the average obtained was 9.5, setting up as well as a high interference, justified because these pregnancies had many complications and significantly affected their bio-psycho-social conditions, and have raised the need for hospitalization in ICU.

\section{Analysis and Interpretation of Narratives}

Women began their narratives with considerations about their pregnancy, emphasizing the fear of losing their child and stressing the importance of prenatal care be focused primarily on the baby's health.

During the prenatal care, I had a lot of questions about what I had and how to treat it, but I was more concerned with my son's health, every time I came to my consultation I would asked the doctor if my son would be fine, if I would need to anticipate my birth and he would be born premature, I was so afraid of that.

Among the doubts reported, according to the narratives, there is highlight to those related to the pathology (pre-eclampsia, high blood pressure, gestational diabetes and HIV) that prompted intensive and indispensable care to prevent complications in pregnancy and childbirth. 
My doubts about pregnancy were about my illness, I wanted to know how it could be transmitted, what to do to not get worse and not to harm my son. When I did my prenatal care in the hospital I liked it more than the in the health unit because there in the hospital the doctor understood more about what I had, she gave me a lot of confidence, she understood well my illness, I truly believed I was going to make it, but I got worse, I think it's because sometimes I did not follow the guidelines, especially with the food. There was one day I felt so much pain and bleeding that I ended up in ICU and my son nearly died. After the birth I ended up returning to the ICU because I had severe bleeding, spent about two months in the ICU, it was very difficult.

In this speech, one can see important parts to be discussed and reflected, as the importance given to the care provided in the hospital at the expense of care delivered in primary care. This may reflect the training of health professionals in the hospital sector to handle risk situations. In addition, there has been attributed great value to the technocratic care. Thus, it is clear that care centered on the biomedical model has still prevailed in the current health scenario. There is a tendency to consider the care as synonymous with technical competence, performance of procedures, etc. [13].

The numerous technical activities often make it difficult approaching to a dimension of care that promotes bonding and integration with the client as well as her approach when she needs comfort and attention to her physical and emotional fragility. This can be seen in several narratives in which women report difficulties in relating to the medical professional on the scene of a risk prenatal care.

Moreover, a relevant factor identified in the speech is the woman's awareness of her responsibility in the care process and outcome of pregnancy, which is a positive point, because the objective of the care provided in prenatal care is to stimulate the autonomy of women in caring for themselves and their pregnancy.

Women have shown much interest in taking care of their health, but their main concern was the health of their child. Thus, it is emphasized the importance of a quality prenatal care that meets their needs. The Ministry of Health considers as quality prenatal care that with early begging, regular, complete and comprehensive coverage [5]. The start of monitoring in the first trimester of pregnancy allows the timely implementation of early diagnosis, preventive and health promotion actions. Furthermore, it allows the identification at the appropriate time of high-risk situations involving the need to refer to other points of care, enabling better care planning.

Prenatal care requires dynamic assessment of risk situations and readiness to identify problems in order to prevent an unfavorable outcome, depending on the problem found. The lack of prenatal care, by itself, may increase the risk to the mother or to the newborn [5]. With the study participants, the risk was discovered in the second trimester of pregnancy, so they were all referred to a public hospital of secondary level for monitoring their risk prenatal care, which is consistent with the recommended by the Ministry of Health.

It is important to note that even before the need for referring high-risk pregnant women for reference services, primary care professionals should continue to follow the evolution of these women. In the study, most mothers reported receiving home visits from Family Health Program teams only after their discharge from the ICU, and that these visits, however, have contributed to the exercise of motherhood.

It was remarkable in the speeches the presence of a significant difficulty in communication that most women had in relation to the medical professionals who conducted their prenatal risk, besides the difficulties to follow the recommended guidelines, especially for not understanding what it was orien- 
ted, a fact associated with the level of education of women and to the primiparous condition of some, which reinforces greater attention.

I found out I had HIV in my prenatal care. I did not quite understand what I had and did not like the way that the doctor talked to me, I did not understand what he was talking and did not know if my child would also have my same disease. I wanted to know more about the disease and how it could harm my baby, but I always left the consultation without understanding. I ended up catching pneumonia and ended up in the ICU, they had to cause my delivery earlier and I could not breastfeed also, but in my prenatal care I was not told that I could not breastfeed the child.

This interview was conducted with a 18-yearsold teenager diagnosed with HIV during her prenatal care. She reported that the child's father is married and was the one who transmitted the virus to her. This participant's speech deserves attention because she is a woman living with HIV diagnosis, concomitant with her pregnancy, requiring specialized care focused on treatment and prevention of opportunistic diseases and on the protection and care of the baby.

The diagnosis during prenatal care enables the delivery of care needed, whereas it is worrying when she mentioned not having a good communication with the physician and that no strategies were carried out to solve this problem, since it is during the prenatal care that women are prepared for motherhood and clarify all their doubts, especially in the context of a sexually transmitted disease such as HIV.

Clarifying doubts and exchange of information between the pregnant woman and the health professional is necessary for understanding the gestational process, to the mother and family satisfaction and, consequently, to a positive evalua- tion regarding the quality of care received14. The care provided in prenatal care needs to consider the implementation of a comprehensive and unique service, which uses communication strategies that, in turn, bring resolute and effective results for pregnant women, especially when it comes to high-risk pregnant women.

Thus, it is believed that the formation of a bond is crucial for the greater involvement of pregnant women in issues relating to their health, the granting of autonomy and the definition of their choices and hence for a more conscious awareness of self-care [15]. It is worth noting that the link between professionals and pregnant women provides greater adherence to prenatal consultations and ensures greater contact of users with information about pregnancy, childbirth and the postpartum period, thus contributing to an exchange of different knowledge among women and professionals.

In addition, health professionals can use health technologies such as the use of questionnaires, scales, equipment, educational materials, among others that contribute to the achievement of care during prenatal care, so that every woman can have their needs met.

Complaints of women regarding the prenatal period were mainly focused on the characteristic signs and symptoms of their diseases that occurred concomitant with pregnancy, which indicates fear of pregnant women in having complications, focusing their concerns mainly on the disease.

(...) During prenatal care I had many consultations, more than my cousin who was also pregnant at the same time as me, because my pregnancy was high-risky, I complained a lot of headache, my vision was bad and I gained a lot of weight, sometimes my blood pressure increased so much that not even remedies solved, I had to go immediately to the emergency. I think the doctor could have taught me more about my illness and I did 
not like the delay in receiving the tests because the tests are very important, right? And it takes a long time there, sometimes I had to do in a private clinic.

As for the approach of professionals in prenatal care, besides the already mentioned, about the difficulty of communication, many of the participants reported that they would like to have received further explanations and guidance on the delivery, breastfeeding, nutrition and about the child care. This result shows the little emphasis given to the guidelines offered throughout pregnancy, as the importance of breastfeeding and breast milk, self-care and child care, among others.

Regarding the procedures performed in the consultations, women mentioned checking blood pressure, maternal weight and measurement of uterine height. In this study, women considered the tests as crucial for the proper monitoring. They expressed satisfaction with the care received from the promptness of the tests, which highlights the importance given by women to the biological and technical care, as can be seen in the following lines:

(...)My doctor was good, in the consultations he always asked tests, because it is very important right?

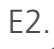

(...)The test is the most important, but I think it takes too long to receive the results, we get worse and does not receive the result.

To perform a quality prenatal care there is need to use updated technical and scientific knowledge, human capital and infrastructure, such as adequate physical space, equipment available for the examination of the woman and the baby, basic medicines, qualified and trained professionals [16]. Within the research axis, through the analysis of women's narratives, it was noticed that the infrastructure was inadequate, some equipment was broken and there was lack of materials for tests, which justified the delay.

Through the women's discourse, authors observed that their emotional aspect remained shaken throughout the prenatal period. Socioeconomic and emotional elements must be considered in the treatment of women and they should be informed about the care needed for the success of this stage. The professional must offer psychological support to the customer, motivating the professional-family interaction through conversations, home visits and group meetings [16].

With regard to the therapeutic journey experienced by women, authors realized that they had a similar trajectory, in which the gateway was the primary care, where they received the diagnosis of pregnancy on average in the $14^{\text {th }}$ week. At the time their pregnancy was diagnosed as risk, they were referred to a more complex service for monitoring their prenatal care, which was performed by a physician and this occurred approximately in the $22^{\text {th }}$ week of pregnancy. All showed the need for ICU admission after delivery, even for a few days, due to complications from pregnancy and childbirth.

In addition, women reported having the memory of despair and fear they felt when admitted in the ICU. Most do not recall events that occurred during hospitalization, but report that they did not realize the time passing and felt concern regarding their life and of their child. The main complications reported by them that led to hospitalization in ICU were hemorrhage, convulsion, pulmonary edema and infections. They could not inform about the causes that led to complications during pregnancy, which is a limitation of the study.

Considering the developing countries, $10 \%$ of admissions in general ICUs are represented by patients in pregnancy and childbirth, and maternal mortality is the highest. In developed countries, the need for hospitalization in ICU for obstetric patients is low. One of the factors the study con- 
siders important to achieve this low rate is the presence of an effective prenatal care [17]. Thus, it is clear the importance of performing an adequate, systematic and effective care during the prenatal period.

Three women revealed a therapeutic journey with greater difficulties, being referred to a non-functioning service due to lack of professionals.

It was hard for me to receive the prenatal care, I almost gave up because they sent me to a place, then sent me to another, not to mention the delay to be seen, and finally I started receiving the prenatal care in another hospital.

In this speech, the interviewee reports the difficulty of carrying out her prenatal care, being referred twice due to lack of vacancy and lack of health professionals, respectively, until finding a service that provided her care. Ensuring access and assistance to pregnant women is one of the objectives of the Stork Network Program and a factor contributing to the reduction of maternal-fetal morbidity and mortality.

Although it has not been conducted a temporal analysis with emphasis on post-deployment repercussions of Stork Network Program, it is recognized that this has brought about new discussions about old problems already discussed at other times in the history of health care to the woman, but which were represented in the media as possible solutions to improve the current situation to which women are subjected when assisted during the pregancypuerperal period in Brazil. It is, therefore, a program to guide health actions for pregnant women, puerperal mothers and newborns.

After receiving discharge from the ICU, women reported having been experiencing their maternity fully, a fact that is very important, because the experience of becoming a mother is, for many women, one of the most intense and significant aspects of human existence [18]. They have been assisted by the Family Health Program team of their community, and have reported feeling better, but the fear of getting pregnant again remains.

\section{Conclusion}

The main doubts of women were mainly directed to the pathology, signs and symptoms. The main difficulties in prenatal consultation were inadequate communication, focus on disease, difficulty in following guidelines and lack of explanations regarding childbirth, breastfeeding, nutrition, child care, and insufficient emphasis on emotional aspects. The therapeutic journey was described partially, because the mothers had difficulties to report on their medical history, especially the causes that led to the appearance of complications in their pregnancy. It was verified, though, that all had a similar journey and there were some difficulties in referrals during prenatal.

It is suggested mare focus of professionals to educational activities to improve prenatal care and to promote sharing of knowledge and interaction, generating a positive impact on physical and emotional health of pregnant women and aimed at solving the problems presented by them, in order to prevent and minimize complications. Moreover, it was noticed also the need to define an organized flow to reference and counter-reference of these pregnant women within the network, as a strategy to prevent complications in the therapeutic journey and consequent negative results for mothers and children.

The results serve as support for the adoption of new health care strategies, conducted by professionals for the care of women during gestation, enabling awareness to change attitudes. Thus, it confirms the importance of future studies aimed at search of health technologies that can contribute to the adoption of adequate and quality prenatal care that is effective and solving for the current reality. 


\section{References}

1. Rodrigues FLG. Pacientes obstétricas em Unidade de Terapia Intensiva. In: Cintra EA, Nishide VM, Nunes WA. Assistência de enfermagem ao paciente gravemente enfermo. 2. ed. São Paulo: Atheneu; 2011.

2. Ministério da Saúde (BR). Secretaria de Atenção à Saúde. Departamento de Ações Programáticas Estratégicas. Gestação de alto risco: manual técnico [Internet]; 5. ed. Brasília (DF): Editora do Ministério da Saúde; 2010. Available from: http:// bvsms.saude.gov.br/bvs/publicacoes/gestacao alto risco.pdf

3. Ministério da Saúde (BR). Centro de Tecnologia de Informações e Serviços do Sistema Único de Saúde (DATASUS). Óbitos maternos. Brasilia [Internet]. Available from: http://tabnet. datasus.gov.br/cgi/tabcgi.exe?sim/cnv/mat10uf.def

4. Queiroz MVO, Marques JF, Jorge MSB, Pinto FJM, Guarita LKS, Menezes NS. Características e agravos prevalentes da população assistida na fase perinatal: Estudo em um hospital terciário do SUS. Rev Min Enferm. 2009; 13(4):565-573. DOI: http://www. dx.doi.org/S1415-27622009000400014

5. Martins EF, Rezende EM, Lana FCF. Causas e evitabilidade dos óbitos perinatais investigados em Belo Horizonte, Minas Gerais. Rev Min Enferm. 2009; 13(4):550-574. DOI: http://www.dx.doi. org/S1415-27622009000400012

6. Fontanella JB, Luschesi BM, Saidel MGB, Turato ER, Melo DG. Amostragem em pesquisas qualitativas: proposta de procedimentos para constatar saturação teórica. Cd Saúde Pública, 2011; 27(2):389-94. DOI: http://dx.doi.org/10.1590/ S0102-311X2011000200020

7. Gomes R, Mendonça EA. A Representação e a experiência da doença: princípios para a pesquisa qualitativa em saúde. In: MINAYO, M.C.S; Deslandes, S.F. Caminhos do pensamento: epistemologia e método. Rio de Janeiro: Fiocruz, 2002.

8. Gomes R. Análise e Interpretação de dados de pesquisa qualitativa. In: MINAYO, M.C.S. Pesquisa Social: teoria, método e criatividade. Petrópolis: Vozes, 2007.

9. Ministério da Saúde (BR). Diretrizes e normas regulamentadoras de pesquisas em seres humanos. Resolução n. 466 de 12 de dezembro de 2012 [Internet]. Brasília: Ministério da Saúde; 2012. Available from: http://conselho.saude.gov.br/resolucoes/2012/ Reso466.pdf

10. Oliveira JFB, Quirino GS, Rodrigues DP. Percepção das puérperas quanto aos cuidados prestados pela equipe de saúde no puerpério. Rev Rene. 2012; 13(1):74-84. Available from: http:// www.revistarene.ufc.br/revista/index.php/revista/article/ view/19/15

11. Sanches NC, Mamede FV, Vivancos RBV. The profile of women who have experienced cesarean section and obstetric care at a public maternity hospital in Ribeirão Preto. Texto Contexto Enferm. 2012; 21(2):418-26. DOI: http://dx.doi.org/10.1590/ $\underline{\text { S0104-07072012000200021 }}$
12. Noronha Neto C, Souza ASR, Amorim MMR. Tratamento da pré-eclâmpsia baseado em evidências. Rev Bras Ginecol Obstet. 2010; 32(9):459-68. DOI: http://dx.doi.org/10.1590/S010072032010000900008

13. Morais FRC, Silva CMC, Ribeiro MCM, Pinto NRS, Santos. Resgatando o cuidado de enfermagem como prática de manutenção da vida: concepções de collière. Rev. enferm. UERJ. 2011; 19(2):305-10. DOI: http://157.86.8.70:8080/certifica/ handle/icict/28949

14. Ministério da Saúde (BR). Secretaria de Atenção à Saúde. Manual técnico pré-natal e puerpério: atenção qualificada e humanizada. Brasília: Ministério da Saúde; 2006. Available from: http://bvsms.saude.gov.br/bvs/publicacoes/manual pre natal puerperio 3ed.pdf

15. Líbera BD, Saunders C, Santos MMAS, Rimes KA, Brito FRSS, Baião MR. Avaliação da assistência pré-natal na perspectiva de puérperas e profissionais de saúde. Ciênc Saúde Coletiva. 2011; 16(12):4855-64. DOI: http://dx.doi.org/10.1590/S1413$\underline{81232011001300034}$

16. Guerreiro EM, Rodrigues DP, Silveira MAM, Lucena NBF. O cuidado pré-natal na atenção básica de saúde sob o olhar de gestantes e enfermeiros. Rev Min Enferm. 2012; 16(3):315-23. DOI: http://www.dx.doi.org/S1415-27622012000300002

17. Oliveira MF, Freitas MC. Diagnósticos e intervenções de enfermagem, freqüentes em mulheres internadas em uma unidade de terapia intensiva. Rev Bras Enferm. 2009; 62(3):3438. DOI: http://dx.doi.org/10.1590/S0034-71672009000300002

18. Souza JP, Pileggi-Castro C. Sobre o parto e o nascer: a importância da prevenção quaternária. Cad. Saúde Pública. 30 Sup: S11-S13, 2014. DOI: http://dx.doi.org/10.1590/0102311XPE02S114

\section{Publish in International Archives of Medicine}

International Archives of Medicine is an open access journal publishing articles encompassing all aspects of medical science and clinical practice. IAM is considered a megajournal with independent sections on all areas of medicine. IAM is a really international journal with authors and board members from all around the world. The journal is widely indexed and classified Q1 in category Medicine. 